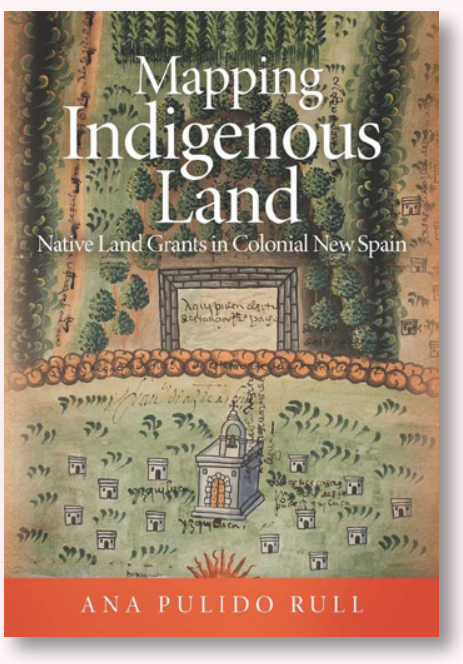

\title{
MAPPING INDIGENOUS LAND: NATIVE LAND GRANTS IN COLONIAL NEW SPAIN
}

\author{
By Ana Pulido Rull \\ University of Oklahoma Press, 2020
}

216 pages, 52 black \& white and 27 color illustrations, 2 maps, 4 tables

Hardcover: \$45.00, ISBN 978-0-8061-6496-0

Review by: Jörn Seemann, Ball State University

In PRE-Columbian times, the Aztec, Maya, Mixtec, and Zapotec peoples of Mesoamerica-the region that historically extended from central Mexico to Costa Ricaall brought forms of visual communication to a high level of development. Included among these forms were sophisticated mapmaking practices. Art historian Barbara Mundy affirms that this kind of mapmaking was a genuinely American achievement that evolved independently from traditions in the Old World, and writes that "these cultures of Mesoamerica took the production and use of maps to a level unparalleled elsewhere in the New World" (Mundy 1998, 183). There are at least four different map types among the surviving artifacts: celestial maps of star constellations and the night sky, cosmographical maps that explained the universe, cartographic histories that visually projected communities and their territories in space and time, and large-scale plans of individual properties (Mundy 1998, 187).

This last category is the object of investigation for Ana Pulido Rull's study of land grant petition maps in the Viceroyalty of New Spain. Created shortly after the arrival of the conquistadors in 1521, the Viceroyalty controlled the Spanish Crown's lands in Mesoamerica. As Spanish colonizers began to seize more and more Indigenous lands for agriculture and cattle herding, Spain became concerned about unlawful occupation, and eager to regulate property holdings. Through its overseas representation, the Viceroyalty, Spain aimed to officially register and control land titles through specific legal proceedings, beginning in 1536. The first step for a Spaniard interested in using land for economic activities was to file a petition for a merced, a land grant, with the Viceroyalty. The request was then sent to the local authorities, who would announce the details about the proposed property, the petitioner, and his intents in a public hearing. Interested parties, both Spaniards and Indigenous, had the right to manifest their support or objection to the request, and this was followed by a field inspection and the questioning of witnesses before the judge pronounced his verdict on the case.

The Archivo General de la Nación in Mexico City holds about 7,500 legal documents on land titles produced during the first two centuries of Spanish colonization. These records include verbal testimony (conversations, attestations, and accounts of conflict), written documents, and over 700 maps with details on measurements, place names, and specific locations, drawn by Indigenous painters or Spanish draftsmen to visualize the land covered by the grant petition. This archival source provides the primary material for Pulido Rull's study, specifically "the corpus of paintings known as land grant maps, or mapas de mercedes de tierras, kept today in the map gallery (Mapoteca) of the Mexican National Archives" (3). Pulido Rull's focus is on the more than 200 works produced by Indigenous artists. This is the first thorough examination of this peculiar set of maps that specifically addresses local land grant disputes, and it parallels Mundy's more general 
official survey of the Relaciones Geográficas between 1579 and 1585 that aimed to collect population data and to map territories in New Spain (Mundy 1996).

Unlike other Spanish territories, land proceedings documentation in New Spain commonly featured a painting of the area where the property was situated. This practice followed the tradition of the Aztec legal system, which used drawings and paintings as narratives and proofs in litigation. In pre-Columbian times, a tlacuilo, or painter-scribe, undertook the recording of all sorts of historical, genealogical, and geographical knowledge, and, as Pulido Rull notes, "there was no distinction between painting and writing: those who created manuscripts wrote using images" (66). This pictorial approach is deeply embedded in the many Mesoamerican visual cultures that commonly emphasized images, pictures, and glyphs as "alternative literacies" over verbal forms of expression (see Leibsohn [2009] and Boone [2010] for fascinating examples).

Within this context, Pulido Rull sets out to read between the lines of these pictorial representations of places and properties, and the accompanying documentation, to find out about how these maps were used as accepted visual arguments, forms of contestation, and strategies of negotiation between Indigenous people and the Spanish colonizers. She argues that these maps by unknown authors served as "cross-cultural communication" (4) and "persuasive and rhetorical images" (5) that expressed distinct views and understandings of the contested lands and were accepted as statements of truth by all participants.

The book is divided into five chapters. In the first, the author provides the historical context for the legal proceedings in land grant processes in New Spain. In theory, the Spanish Crown only allowed requests to be filed for demonstrably vacant lands, as a form of protection for the Indigenous population that had cultivated fields and herded animals in this region for a long time. However, the court records show that the application of land grant laws had many loopholes and a lot of room for corruption, fraud, and dishonesty - to the great disadvantage of Indigenous landowners. The chapter describes in detail how judges, scribes, translators, painters, and involved parties communicated and interacted from the moment of the official reading of the request-which frequently occurred after Sunday mass - to the final decision about the land ownership.
Chapter 2 focuses on the Indigenous artists and the painting process itself. The land grant maps blended pre-Columbian Indigenous pictorial traditions with elements of Renaissance art introduced by European monks from mendicant orders, who came to Mesoamerica to catechize and educate the Indigenous people, and who also taught them to paint religious motifs on church and monastery walls. As a result of this cultural encounter, the maps frequently contained both conventional Indigenous glyphs and European elements and techniques, such as human figures, scale, and perspective. Many of the resulting maps included pre-Columbian pictographs for houses, paths with human footprints for designated roads, whirlpools for water bodies, bell-shaped hill symbols for elevations, and trees with exposed roots. These sophisticated, colorful paintings in Pulido Rull's study were painted with locally available pigments extracted from flowers, seeds, insects, or minerals on paper either imported from Europe or made from local fig-bark or agave fibers.

The remaining three chapters of the book discuss particular land dispute cases in different stages of the process during which grants were requested, opposed, and negotiated. Pulido Rull presents detailed narratives of the court documents and the property maps. Chapter 3 tells about the case of Andrés de Arellano, the Indigenous governor of Pahuatlán, who requested two ranches for small cattle herding in the proximity of the town. The colorful pictorial land grant map depicts hills and mountains (in green, with tree symbols), a standardized church symbol for all settlements, and brown tones for roads. The plains between the elevations are painted in light yellow, "which creates a sense of depth" (85). The two properties for the land grant are at the bottom of the map (west), and are less carefully drawn in the form of rectangular fenced areas. Arellano's petition was approved within two days, because the ranches "would not bring harm to a third party." (83)

Many cases did not reach the quick resolution of the example above. In Chapter 4, Pulido Rull sheds light on multiple processes through which Indigenous people opposed requests by Spaniards because the proposed herding grounds were too close to Indigenous properties, and they feared damage to their crops or the contamination of their water sources. In the case of a petition in the town of Coatlinchan, a Spaniard requested lands for two small animal ranches-claiming that these lands were vacant, even though the Indigenous people declared that they had used them for a long time and even had received a property 
title signed by a former mayor. A few days after the initial hearing, another Spaniard submitted a request for lands close to the area of the first petition. The maps used in this dispute show heavy reworking. Places crucial to the argument of the Spanish petitioners were amended: patches of paper were glued on top of the original map, farms were displaced to "safe" positions, and an entire cornfield even disappeared from the map-all in order to make points for the Spaniard's argument. Infrared photos clearly show palimpsest evidence of this meddling with the map's contents. The result of the lawsuit was the unanimous approval of the petition by both Spanish and Indigenous witnesses-an outcome that could indicate collusion, coercion, or even bribery (118).

Unfortunately, many cases were decided in favor of the Spanish petitioners, despite the questionable quality of their evidence or argument. This systemic partiality induced many Indigenous people, who at first contested the requests, to attempt to negotiate, and, ultimately, to withdraw their veto, as the author shows in Chapter 5. Five years after the decision about the land grants in Coatlinchan, the Spaniard Diego de Villegas also petitioned for land to open two cattle farms. His request was approved swiftly, despite the fact that another Spaniard who had applied for the same lands four years earlier had been rejected. In this particular case, Pulido Rull can only speculate on the chain of events that made witnesses change their mind, suggesting that giving in might help them to receive "some benefits and establish a good relationship with the new landholder" (160).

Pulido Rull's account is very engaging and reads like a collection of detective story plots with cartographic crimes and historical "story maps." Her patient deciphering of court documents allows her to reconstruct crucial parts of the judicial proceedings and the more than 50 blackand-white illustrations and 27 color plates showing complete maps or zoomed-in details give what seems likely as clear an understanding of the issues and arguments as was available to the judges. Altogether Pulido Rull shows not only that these cross-cultural maps were powerful tools to represent reality, but also how that representation could be altered or reworked to reflect changes in how someone wishes that reality to be presented. Cartographic palimpsests-that is, areas on a map that have been scraped off, overwritten or covered with other pieces of paper-were not uncommon among the land grant maps, and clearly represented shifts in a petitioner's argument in order to gain or maintain advantage.

It would have been useful for the author to devote some time early in the book to discussing the theoretical framework within which she places her cartographic study, but it is only in the book's conclusion that the author alludes to the work of J. B. Harley and his ideas about the rhetoric of maps and their propositional character. Presenting this discussion earlier would have set the stage for her analysis of the land grant maps and how these were used as visual arguments, albeit most frequently in favor of the colonizers. Although Pulido Rull's intention is to point out that there was a distinctly Indigenous dimension in the mapping process for land grants-one that is still visible in the archives despite the widespread erasure of historical Indigenous traces in the Americas-the reader may gain the impression that she tries to extract more facts on Indigenous mapmaking from the documents than what she could, in fact, find. Due to the scarcity of original Indigenous records, and to the almost overpowering presence of the "paper bureaucracy" of the Spanish colonial administration, information about Indigenous society in general and mapmakers in particular is scarce. Nonetheless, her study shows the powerlessness of the Indigenous population suffering encroachment on their traditional lands, and the partiality of the legal system that very frequently dismissed their concerns. On the other hand, signs of hope can also be found. For example, she discusses one of the few lawsuits decided in favor of the Indigenous people, when a land grant for a limestone quarry was subsequently revoked and the public prosecutor requested that the Spanish petitioner and his workers "be taken in custody and formally charged" (17). The court documents do not tell if this request was executed, but it seems clear that the Indigenous landowners were able to secure their lands.

I feel that the author could have engaged with the issues and questions surrounding postcolonial and decolonial cartography more deeply than she did (see, for example, Akerman [2017]). Engaging these issues would have helped contextualize her study and make a stronger statement about the importance of Indigenous maps and cultural perspectives in the history of cartography-a history that for a long time has maintained a biased view of non-Western or "primitive" maps. 
Mapping Indigenous Land includes glossary of more than one hundred Spanish and Nahuatl technical terms with explanations of their specific meanings, some of which can be difficult to understand from a modern Western perspective. The illustrations of historical paintings are fascinating, but I have a minor complaint about some of the contemporary maps used in the book. It would be useful to add a general map showing the locations of the land grant cases and documentary paintings discussed. This would have been of tremendous help for those readers not already familiar with the historical geography of Mesoamerica; more help than the catalog of land grant maps that is included in the appendix. Although there were two location maps with a relief background (Figures 5.1 and 5.4), they are disproportionately large and not very informative, adding very little to the text. Nonetheless, these small issues do not take away any of the merit of this captivating study. In conclusion, Mapping Indigenous Land is a pleasant and entertaining read that provides insights into stories of mapmaking at the contact zone between Mesoamerican and European cultures. The book will definitely spark the interest of those readers who are not only curious about historical maps from New Spain, but also about maps as storytelling devices and as visual arguments.

\section{REFERENCES}

Akerman, James, ed. 2017. Decolonizing the Map: Cartography from Colony to Nation. Chicago: University of Chicago Press.

Boone, Elizabeth H. 2010. Stories in Red and Black: Pictorial Histories of the Aztecs and Mixtecs. Austin: University of Texas Press.

Leibsohn, Dana. 2009. Script and Glyph: Pre-Hispanic History, Colonial Bookmaking, and the Historia ToltecaChichimeca. Washington, DC: Dumbarton Oaks Research Library and Collection.

Mundy, Barbara. 1996. The Mapping of Nerw Spain: Indigenous Cartography and the Maps of the Relaciones Geográficas. Chicago: University of Chicago Press.

1998. Mesoamerican Cartography. In The History of Cartography, Volume II, Book III: Cartography in the Traditional African, American, Arctic, Australian, and Pacific Societies, edited by David Woodward and G. Malcolm Lewis, 183-256. Chicago: University of Chicago Press. 